\title{
Review: smooth muscle relaxants improve symptoms and reduce pain in irritable bowel syndrome
}

Poynard T, Regimbeau C, Benhamou Y. Meta-analysis of smooth muscle relaxants in the treatment of irritable bowel syndrome. Aliment Pharmacol Ther 2001 Feb;15:355-61.

\section{QUESTION: In patients with the irritable bowel syndrome (IBS), are smooth muscle relaxants safe and efficacious for global improvement of symptoms?}

\section{Data sources}

Randomised controlled trials were identified by searching Medline with the terms colonic disease, functional, irritable bowel syndrome, and randomised trial; Current Contents; and bibliographies of relevant trials, metaanalyses, and reviews. Drug companies were also contacted.

\section{Study selection}

Trials were selected if they were double blind studies that compared muscle relaxants with placebo, $\geqslant 51 \%$ of patients had IBS, the drugs studied had myorelaxant properties, and $\geqslant 1$ end point of global assessment of symptoms, abdominal pain, constipation, or abdominal distension was included.

\section{Data extraction}

Data were extracted on study quality, patient characteristics and numbers, drug and dosage, treatment duration, and outcomes.

\section{Main results}

23 trials (1888 patients) met the inclusion criteria. 6 drugs were studied: cimetropium bromide (5 trials), hyoscine butyl bromide (3 trials), mebeverine ( 5 trials), otilium bromide ( 4 trials), pinaverium bromide (2 trials), and trimebutine (4 trials). All drugs analysed together and each drug analysed separately, except pinaverium alone, showed improvement in global symptom ratings (table). All drugs combined (and otilium and cimetropium alone) reduced pain (table). Abdominal distension was improved with all drugs (table), but constipation or transit was not. The percentage of patients with adverse effects did not differ for all drugs compared with placebo or for individual drugs.

\section{Conclusion}

Smooth muscle relaxants improve the global rating of symptoms and reduce pain in patients with irritable bowel syndrome.

Smooth muscle relaxants v placebo for irritable bowel syndrome (trial duration 3 d to 24 wks)*

\begin{tabular}{|c|c|c|c|c|c|c|}
\hline \multirow[b]{2}{*}{ Improvements } & \multirow[b]{2}{*}{ Drug } & \multirow{2}{*}{$\begin{array}{l}\text { Number of } \\
\text { studies }\end{array}$} & \multicolumn{2}{|c|}{ Unweighted event rates } & \multirow[b]{2}{*}{ RBI $(95 \%$ Cl) } & \multirow[b]{2}{*}{ NNT (Cl) } \\
\hline & & & Drug & Placebo & & \\
\hline \multirow[t]{6}{*}{ Global } & All & 22 & $56 \%$ & $38 \%$ & $49 \%$ (37 to 61$)$ & $6(5$ to 8$)$ \\
\hline & Mebeverine & 4 & $52 \%$ & $37 \%$ & $47 \% \quad(9$ to 84$)$ & $4(6$ to 31$)$ \\
\hline & Cimetropium & 5 & $60 \%$ & $40 \%$ & $63 \%(29$ to 92$)$ & $4(3$ to 9$)$ \\
\hline & Trimebutine & 4 & $53 \%$ & $24 \%$ & $98 \%$ (63 to 117$)$ & $5(4$ to 7$)$ \\
\hline & Otilonium & 3 & $97 \%$ & $34 \%$ & $60 \%$ (33 to 87$)$ & $5(4$ to 9$)$ \\
\hline & Hyoscine & 3 & $53 \%$ & $42 \%$ & $26 \% \quad(7$ to 124$)$ & 10 (2 to 32$)$ \\
\hline \multirow[t]{3}{*}{ Pain } & All & 11 & $53 \%$ & $41 \%$ & $30 \%(16$ to 45$)$ & $9(6$ to 16$)$ \\
\hline & Otilium & 3 & $47 \%$ & $29 \%$ & $62 \%$ (30 to 96$)$ & $7(4$ to 12$)$ \\
\hline & Cimetropium & 1 & $87 \%$ & $27 \%$ & $198 \%$ (81 to 253$)$ & 2 (2 to 5$)$ \\
\hline Distention & All & 6 & $44 \%$ & $35 \%$ & $26 \% \quad(6$ to 46$)$ & 12 (7 to 46$)$ \\
\hline
\end{tabular}

*Abbreviations defined in glossary; RBI, NNT, and $\mathrm{Cl}$ calculated from data in article.

\section{COMMENTARY}

IBS represents a heterogeneous group of disorders presenting with similar clinical symptoms. Altered motility is thought to be important in a subset of patients with IBS, and this concept forms the foundation for the use of smooth muscle relaxants.

3 recent meta-analyses, including the review by Poynard $e t$ $a l$, have evaluated smooth muscle relaxants for IBS. ${ }^{12}$ Each found such agents better than placebo for global improvement and abdominal pain. The latest, the review by Poynard et al, differs from its predecessors by excluding peppermin oil and dyciclomide bromide and including 6 additional randomised, non-English language trials. Although smooth muscle relaxants appear superior to placebo, Poynard et al suggest that only approximately $50 \%$ of treated patients will experience global improvement and only 40\% will have an improvement in abdominal pain. In addition, the results do not indicate which individuals are most likely to improve with these agents. Perhaps most important, only 1 of the drugs included in this meta-analysis, hyoscine, is available in the US, and it showed the least benefit for global improvement or abdominal pain over placebo.

If one accepts the issues noted above, it seems reasonable to conclude that as a class, smooth muscle relaxants can benefit a subset of patients with IBS. Unfortunately, whether the results are generalisable to agents available to physicians in the US remains an open question.

William D Chey, MD University of Michigan Health Systems Ann Arbor, Michigan, USA

1 Poynard T, Naveneau S, Mory B, et al. Meta-analysis of smooth muscle relaxants in the treatment of irritable bowel syndrome. Aliment Pharmacol Ther 1994;8:499-510.

2 Jailwala J, Imperiale T, Kroenke K. Pharmacologic treatment of the irritable bowel syndrome: a systematic review of randomized, controlled trials. Ann Intern Med 2000;133:136-47.

Source of funding: in

part, Solvay

Pharmaceutical

Company.

For correspondence:

Dr T Poynard, Service d'Hépato-

Gastroentérologie,

Groupe Hospitalier

Pitié-Salpêtrière

47-83, Boulevard de

l'Hôpital 75651, Cedex

13, Paris, France. Fax

$+33140779596$ 